\title{
Cooling System Temperature Control Using PIC Microcontroller
}

\author{
Rayan Mohamed Hamid ${ }^{1}$, Eltahir Mohamed Hussein ${ }^{2}$ \\ ${ }^{1}$ Department of Control, Faculty of Engineering, Al-Neelain University, Sudan \\ ${ }^{2}$ Associate Professor, Biomedical Engineering Department, College of Engineering, Sudan University of Science and Technology(SUST), \\ Sudan
}

\begin{abstract}
This paper discuss how was to design and study how to control the operations of cooling as the cooling power change automatically without human intervention by the set temperature and low degrees of cooling gradually when approaching ideal class. This project is to control the DC motor application by using GUI in C\# visual studio and PIC controller. There are two modes to controller the DC motor application. The first mode is control the DC motor directly. For the second mode is to control the DC motor we use the analog temperature sensor to detect the current temperature and measured the value of temperature. The important of this project is to interface the PC C\# visual studio GUI with the PIC microcontroller. Then, the important part of this project is to receive a signal from sensor that will transmit PIC microcontroller. After that, the programming will send the signal to control the motor application automatically.
\end{abstract}

Keywords: DC motor, PIC Microcontroller, GUI, Serial communication

\section{Introduction}

In this part discuss about what is the method that has been used to complete this project. It describes on how the project is organized and the flow of the steps in order to complete this project. The methodology is consoled of two parts, which is developing programming for PIC Microcontroller to control speed of DC motor for cooling systems. The other part is developing hardware these system to interface with C\# visual studio in PC.

The most important parts in the cooling systems are the fans. Controlling these fans controls in term the degree of the cooling. Increasing or decreasing the fans speed affect directly by temperature degree, which could be measured by sensor, then converted into a digital quantity by analog to digital converter module within microcontroller depending on this degree the microcontroller will control required degree.

The system includes a graphical user interface by c\# studio program in the computer that connected microcontroller and computer via serial port. Protues 7 program has been used in testing and simulation the project.

\section{Objectives}

The main objectives of this design are to:

- To control the automated cooling process (motor speed) by PIC microcontroller.

- Applying computer control via serial port and GUI.

\section{Problem Statement}

The purpose of this project is how controlling by microcontroller with a computer (PC) in a number of applications, using an interpreter for the process control DC motor speed to increase or reduce the severity of cooling through the controlled microcontroller PIC by the programming language micro $\mathrm{c}$ or assembly and programming graphical user interface $\mathrm{C \#}$ visual studio to use the computer also in the process of manual control of cooling

\section{Methodology}

In this research the following procedures and steps were taken:

- Building up the software.

- Running simulations programs.

- Hardware design.

- Comparison of simulation results with those obtained from experimental test.

\section{Hardware Design}

This part explains more about the hardware design and construction involves in this project.

\section{1) PIC Microcontroller}

PIC is a family of modified Harvard architecture microcontrollers made by Microchip Technology, derived from the PIC1650 originally developed by General Instrument's Microelectronics Division. The name PIC initially referred to "Peripheral Interface Controller". PICs are popular with both industrial developers and hobbyists alike due to their low cost, wide availability, large user base, and extensive collection of application notes, availability of low cost or free development tools, and serial programming and re-programming with flash memory capability. 


\section{International Journal of Science and Research (IJSR) \\ ISSN (Online): 2319-7064}

Index Copernicus Value (2013): 6.14 | Impact Factor (2015): 6.391

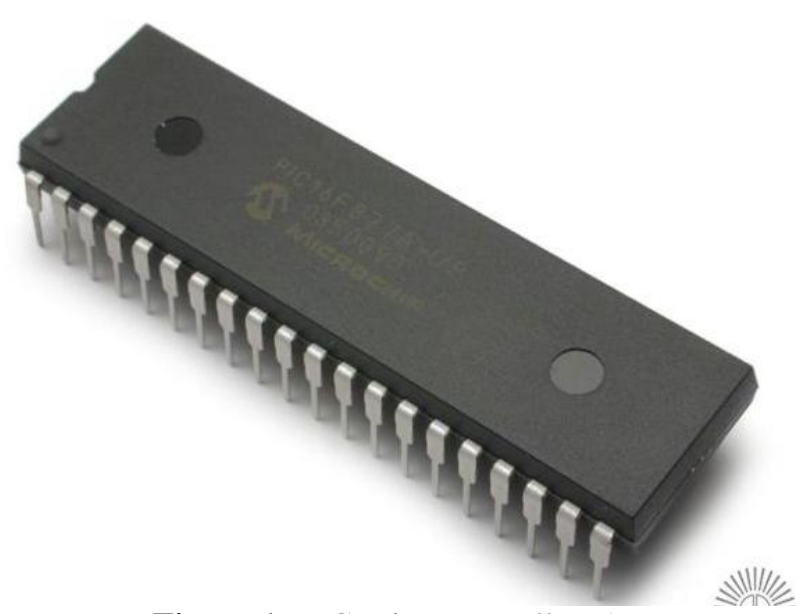

Figure 1: PIC Microcontroller [1]

\section{2) Temperature Sensor (LM35)}

An analog temperature sensor is pretty easy to explain, its a chip that tells you what the ambient temperature. These sensors use a solid-state technique to determine the temperature. That is to say, they don't use mercury like old thermometers, bimetallic strips like in some home thermometers or stoves, nor do they use thermistors (temperature sensitive resistors). Instead, they use the fact as temperature increases, the voltage across a diode increases at a known rate. (Technically, this is actually the voltage drop between the base and emitter. By precisely amplifying the voltage change, it is easy to generate an analog signal that is directly proportional to temperature. There have been some improvements on the technique but essentially that is how temperature is measured. [2]

The LM35 thus has an advantage over linear temperature sensors calibrated in ${ }^{\circ}$ Kelvin, as the user is not required to subtract a large constant voltage from its output to obtain convenient Centigrade scaling. The LM35 does not require any external calibration. It can be used with single power supplies, or with plus and minus supplies

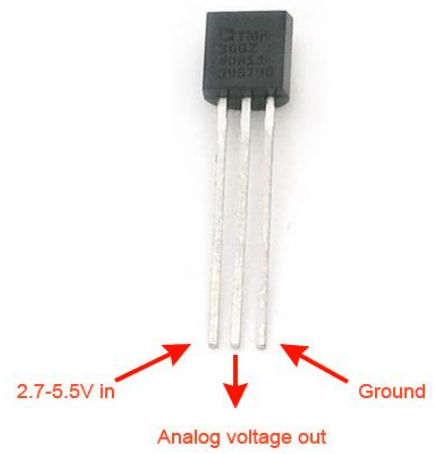

Figure 2: LM35 [2]

\section{3) Serial Communications}

The RS-232 interface is the Electronic Industries Association (EIA) standard for the interchange of serial binary data between two devices. It was initially developed by the EIA to standardize the connection of computers with telephone line modems. The standard allows as many as 20 signals to be defined, but gives complete freedom to the user. Three wires are sufficient: send data, receive data, and signal ground. The remaining lines can be hardwired on or off permanently. The signal transmission is bipolar, requiring two voltages, from 5 to 25 volts, of opposite polarity [3]

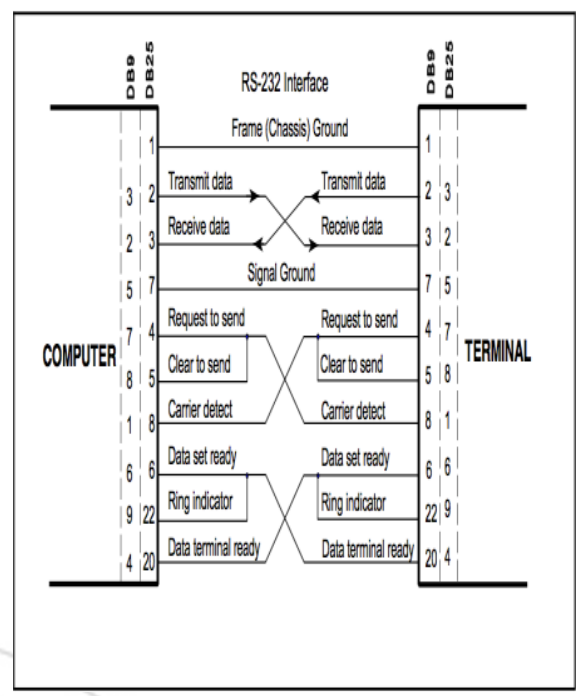

Figure 3: RS-232 Interface [3]

\section{4) MAX 232 IC}

MAX232 is compatible with RS-232 standard, and consists of dual transceiver. Each receiver converts TIA/EIA-232-E levels into $5 \mathrm{~V}$ TTL/CMOS levels. Each driver converts TTL/COMS levels into TIA/EIA 232-E levels. The MAX232 is characterized for operation from $-40^{\circ} \mathrm{C}$ to $+85^{\circ} \mathrm{C}$ for all packages. MAX232 is purposed for application in highperformance in- formation processing systems and control devices of wide application [7]

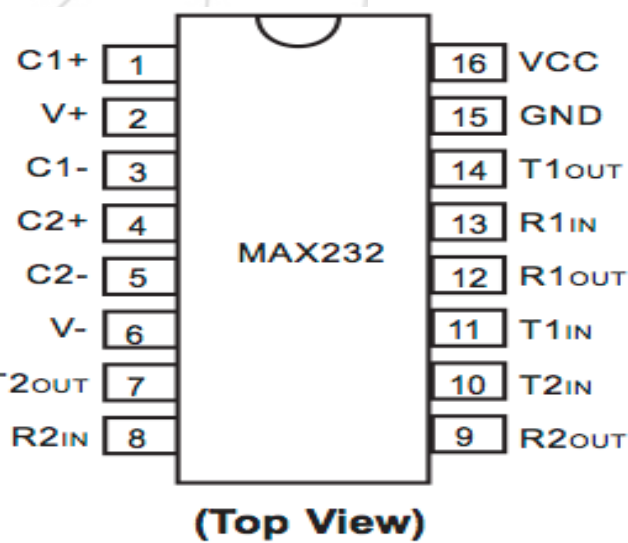

Figure 4: MAX232 IC Top View [4]

\section{5) Liquid Crystal Display (LCD)}

A liquid crystal display (LCD) is a flat panel display, electronic visual display, or video display that uses the light modulating properties of liquid crystals. LCs do not emit light directly. This type of simplified types of LCD display $16 * 2$ is connected with microcontrollers to view the results and all that wish to vulnerable LCDs are used in a wide range of applications, including computer monitors, television, instrument panels, aircraft cockpit displays, signage, etc. [5]

\section{6) DC Motor}

A DC motor in simple words is a device that converts direct current (electrical energy) into mechanical energy. It's of 


\section{International Journal of Science and Research (IJSR) \\ ISSN (Online): 2319-7064}

Index Copernicus Value (2013): 6.14 | Impact Factor (2015): 6.391

vital importance for the industry today, and is equally important for engineers to look into the working principle of DC motor in details that has been discussed in this article. In order to understand the operating principle of dc motor we need to first look into its constructional feature [6].

\section{Building and Programming the Microcontroller}

The microcontroller was programmed following several steps which principally are:

The program was been written in $\mathrm{C}$ language using micro $\mathrm{c}$ compiler This program is compiled so as to generate a hexadecimal file (HEX).the PIC microcontroller is placed into the programmer and the HEX file transferred to the microcontroller through the programmer software.

\section{Software Section}

For the proper functioning of the system first step is simulation the system by protus software and using Visual Studio 2010 for Graphical User Interface (GUI) purpose

\subsection{Graphical User Interface (GUI)}

In computing, a graphical user interface GUI, commonly pronounced gooey is a type of user interface that allows users to interact with electronic devices with images rather than text commands. GUIs can be used in computers, handheld devices such as MP3 players, portable media players or gaming devices, household appliances and office equipment. A GUI represents the information and actions available to a user through graphical icons and visual indicators such as secondary notation, as opposed to text-based interfaces, typed command labels or text navigation. The actions are usually performed through direct manipulation of the graphical elements [7]

Visual Studio 2010 is a set of tools in a single application that helps you writes programs, you would need to open a text editor, write all of the code, and then run a commandline compiler to create an executable application. The issue with the text editor and command-line compiler is that you would lose a lot of productivity through manual processes [8]. Visual Studio supports different programming languages by means of language services, which allow the code editor and debugger to support to varying degrees nearly any programming language [9]

The GUI of the project is designed by Microsoft visual studio C\# 2010 in Computer (PC) to control the work of the project manually by selecting the speed of DC motor appropriate and choose the mode of operation whether the operation of automatic or manual operation of the cooling system, and connection microcontroller with the computer by the serial port, and there is a special IC of the process of the interface and protocol connection UART to transfer data between computer microcontroller

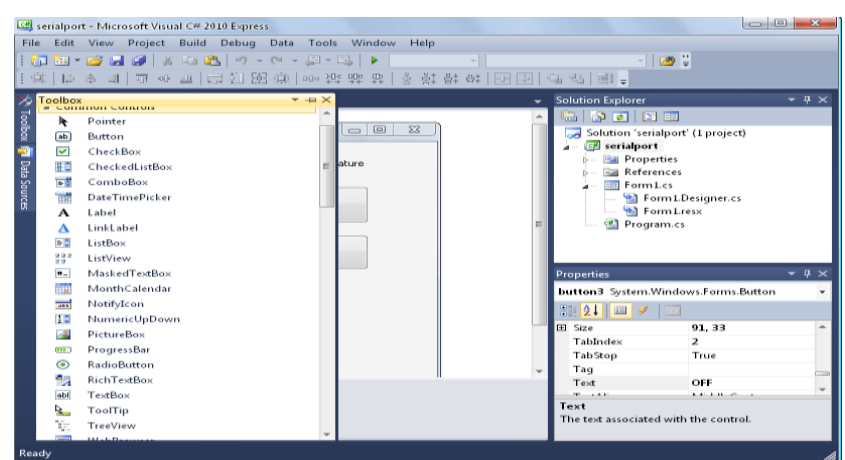

Figure 5: Visual C\# Workspace Window

The figure below represents a graphical user interface (GUI) to control by the computer in the cooling system where the computer is in this case control over the automatic control or what is called the 2 levels of control

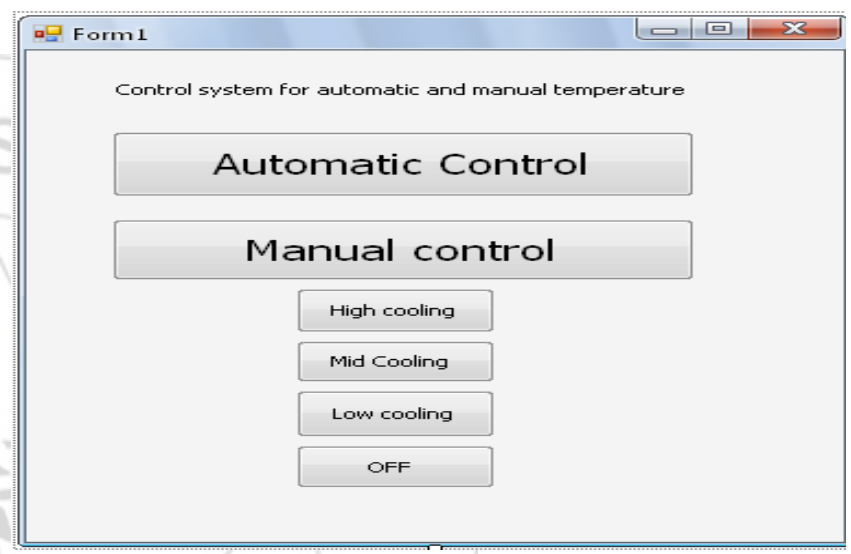

Figure 6: Main GUI Control Window by Visual C\# in PC

The figure below shows the Circuit Connections in Proteus

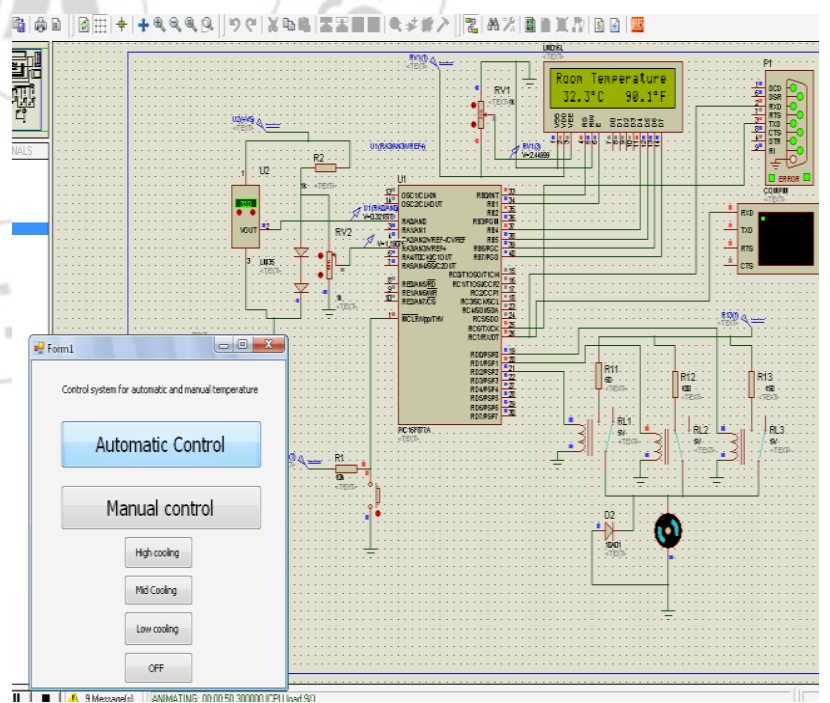

Figure 7: Shows the simulation result for the whole system after the developed program code was loaded into the microcontroller

\section{Hardware Result}

The result and discussion of this project and find out the obstacles and how to treat and ways to search for solutions and obtain the required results as far as possible, and the possibility of origin had to add a tool for process control of 


\section{International Journal of Science and Research (IJSR) \\ ISSN (Online): 2319-7064}

Index Copernicus Value (2013): 6.14 | Impact Factor (2015): 6.391

multi-level in order to give the property control over the automatic control and determine the final results of this project

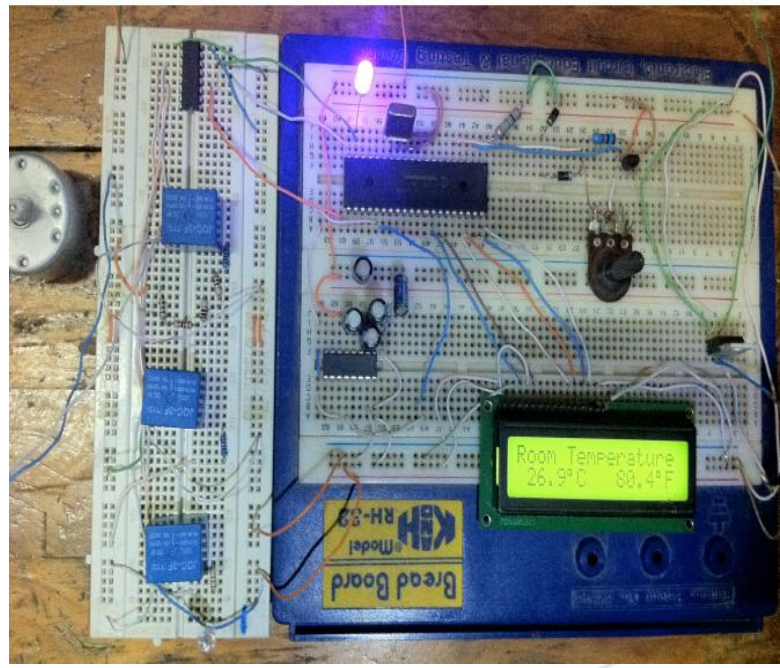

Figure 8: Hardware Circuit

\section{Applications}

- Can be used in factory automation.

- Can be use machine control

- Medical equipment and devices.

- Chemical process, electric trains, robotics and manipulators.

\section{Conclusion}

The goal of this project is to identify the best method to find a way optimal control mechanism to maintain the proper temperature in the selected area by increasing and reducing the cooling controlled by microprocessor and the increase and decrease in cooling through the change-speed fan (DC motor). In this project the change in speed was not very clear because we used the 9-volt motor, but in practical applications are cooling fans by high-voltage motors may be of a $\mathrm{DC}$ or $\mathrm{AC}$, where the change in speed more clearly.

\section{References}

[1] http://en.wikipedia.org/wiki/PIC_microcontroller access on $22 / 1 / 2016$

[2] http://en.wikipedia.org/wiki/Sensor access on 06/1/2016

[3] The RS-232 Standard. From www.omega.com

[4] max232 data sheet. From www.chipswinner.com

[5] http://en.wikipedia.org/wiki/LCD on 16/10/2015

[6] http://www.electrical4u.com/working-or-operatingprinciple-of-dc-motor/ access at 25/1/2016

[7] Ziff Davis . PC Magazine. Publishing Holdings Inc. Retrieved 12 November 2008.

[8] Joe Mayo, Microsoft Visual Studio Beginner's Guide, San Francisco, 2009.

[ 9 ] http://en.wikipedia.org/wiki/Microsoft_Visual_C on $24 / 06 / 2012$ 